\title{
COVID-19 impact assessment on the French radiological centers: a nationwide survey
}

\author{
Guillaume Herpe ${ }^{1,2}$ (1) $\cdot$ Mathieu Naudin ${ }^{2} \cdot$ Mathieu Léderlin $^{3} \cdot$ Farida Enikeeva $^{2} \cdot$ Olivier Boumendil $^{4}$. \\ Lucie Cassagnes $^{5} \cdot$ Madeleine Cavet $^{6} \cdot$ Kathia Chaumoitre $^{7} \cdot$ Philippe Feuerstein $^{8} \cdot$ Isabelle Fitton $^{9} \cdot$ Violaine Flory $^{10}$. \\ Cornelia Anna Freitag ${ }^{11}$. Jean Yves Gaubert ${ }^{12}$. Jules Gregory ${ }^{13} \cdot$ Hubert Nivet $^{14}$. Mickaël Ohana ${ }^{15}$. Isabelle Petit ${ }^{16}$. \\ Nicolas Sans ${ }^{17} \cdot$ Mathilde Wagner $^{18} \cdot$ Rémy Guillevin $^{19} \cdot$ Pierre-Jean Saulnier $^{20}$ • Jean-Michel Bartoli ${ }^{21}$. \\ Jean Pierre Tasu ${ }^{22} \cdot$ Jean-Paul Beregi ${ }^{23}$
}

Received: 12 May 2020 / Revised: 5 June 2020 / Accepted: 12 June 2020 / Published online: 3 July 2020

(C) European Society of Radiology 2020

\begin{abstract}
Purpose To determine the impact of the COVID-19 on the CT activities in French radiological centers during the epidemic peak. Materials and methods A cross-sectional prospective CT scan survey was conducted between March 16 and April 12, 2020, in accordance with the local IRB. Seven hundred nine radiology centers were invited to participate in a weekly online survey. Numbers of CT examinations related to COVID-19 including at least chest $\left(\mathrm{CT}_{\text {covid }}\right)$ and whole chest $\mathrm{CT}_{\text {scan activities }}\left(\mathrm{CT}_{\text {chest }}\right)$ were recorded each week. A sub-analysis on French departments was performed during the 4 weeks of the study. The impact of the number of RT-PCRs (reverse transcriptase polymerase chain reactions) on the CT workflow was tested using two-sample $t$ test and Pearson's test.

Results Five hundred seventy-seven structures finally registered (78\%) with mean response numbers of $336 \pm 18.9(323 ; 351)$. Mean $\mathrm{CT}_{\text {chest }}$ activity per radiologic structure ranged from $75.8 \pm 133(0-1444)$ on week 12 to $99.3 \pm 138.6(0-1147)$ on week 13 . Mean ratio of $\mathrm{CT}_{\text {covid }}$ on $\mathrm{CT}_{\text {chest }}$ varied from 0.36 to 0.59 on week 12 and week 14 respectively. There was a significant relationship between the number of RT-PCR performed and the number of $\mathrm{CT}_{\text {covid }}\left(r=0.73, p=3.10^{-16}\right)$ but no link with the number of positive RT-PCR results.

Conclusion In case of local high density COVID-19, CT workflow is strongly modified and redirected to the management of these specific patients.

Key Points

- Over the 4-week survey period, 117,686 chest $C T\left(C T_{\text {total }}\right)$ were performed among the responding centers, including 61,784 (52\%) CT performed for COVID-19 (CT

- Across the country, the ratio $C T_{\text {covid }} / C T_{\text {total }}$ varied from 0.36 to 0.59 and depended significantly on the local epidemic density $(p=0.003)$.

- In clinical practice, in a context of growing epidemic, in France, chest CT was used as a surrogate to RT-PCR for patient triage.
\end{abstract}

Keywords COVID-19 $\cdot$ Radiology $\cdot$ Surveys and questionnaires $\cdot$ Tomography $\cdot$ X-Ray computed $\cdot$ Prospective

Summary statement Over the 4 weeks of the nationwide epidemic peak, some general demographics have significantly impacted overall chest CT activity and more specifically the COVID-19 CT-related activity.

Electronic supplementary material The online version of this article (https://doi.org/10.1007/s00330-020-07035-w) contains supplementary material, which is available to authorized users.

Guillaume Herpe

guillaume.herpe@chu-poitiers.fr

Extended author information available on the last page of the article

\section{Introduction}

The 2019-2020 coronavirus infection is an ongoing pandemic of coronavirus disease 2019 (COVID-19) caused by severe acute respiratory syndrome coronavirus 2 (SARS CoV2). As of April 15, 2020, more than 2 million cases of COVID-19 had been reported in 210 countries and territories, resulting in more than 128,000 deaths [1]. On January 10, 2020, health authorities implemented a monitoring system for COVID-19 $[2,3]$. Since week 12 (Monday, March 16), France has entered 
the epidemic phase with a circulation of SARS CoV2 throughout the French territory. A dedicated epidemiological survey was issued by health authorities from that day [3]. During this pandemic, the radiological centers had to face an unprecedented situation; on March 12, the first recommendations from the health authorities were issued to decrease potential contamination for subsequent patients [4-8]. Non-urgent examinations were deprogrammed and specific hygiene measures surrounding the CT scan activity of patients suspected of COVID-19 were established. The impact of these new organizations on radiology department activities and how the recommendations were applied has remained largely unknown [9].

As a result, we conducted an active, CT-based prospective survey during the 4 weeks of the epidemic peak in French territory in order to determine the impact of the SARS CoV2 infection on the CT scan activities [10].

\section{Materials and methods}

An active, CT scan-based, prospective epidemiological survey study was conducted between March 16 and April 12, 2020 (week 12 to week 15). This study was approved by the local Institutional Review Board and was carried out in accordance with the 1964 Helsinki Declaration and its later amendments. Since there were no specific patient data collected, informed patient consent was not required. An external scientific committee including recognized scientists (JM.B, JP.B, M.L, and PJ.S) was established to evaluate the different versions of the survey, to ensure the control of the protocol and the global quality of this study. All members are guarantors of the scientific content of this study.

Study area and survey This is a prospective study with a retrospective analysis based on declarative forms. Studied centers were identified through the French Society of Radiology and the College of French Teacher-Researchers in Radiology among the 709 radiology centers with a CT scan representing $1200 \mathrm{CT}$ devices [11]. For each center, a referring radiologist identified by his or her first name, e-mail address, and position as private radiologist, junior radiologist, senior public health radiologist, or Professor of Radiology, was in charge of the study. Considering that analysis was carried out per radiology centers, local activity of a potential teleradiology company was merged with the on-site activities. A survey form was sent to the referring radiologist each week and reminders were sent twice a week by e-mail.

The survey form included the following parameters:

(i) Center identification number, type of center according to 3 levels (university hospital, public hospitals, private radiology center). (ii) Number of chest computed tomography $\left(\mathrm{CT}_{\text {chest }}\right)$ scans were defined as all CT scans including at least chest. Among them, we recorded the overall amount of CT scans in COVID-19 context (at the initial diagnosis or the follow-up), named $\mathrm{CT}_{\text {covid }}$.

(iii) Potential equipment dedicated for COVID-19 imaging and its nature (CT, mobile and standard X-ray devices, MRI, US devices).

From this survey, a ratio called $\mathrm{CT}_{\text {covid }}$ rate was computed from the formula $\mathrm{CT}_{\text {covid }} / \mathrm{CT}_{\text {chest. }}$ Internal and external validity tests for the survey were performed to address potential bias [11]:

(i) For internal validity, a first pilot version of the survey form was tested on a randomized selected group of 10 centers (1 university hospital, 3 local hospitals, and 6 private centers). The results of this first survey were excluded from the final analysis. The final version of the survey form was obtained by taking in account remarks from this testing period and validated by the scientific committee.

(ii) For external validity, discrepancies between complementary questions in the questionnaire were scanned automatically and correction(s) had to be made by the referring radiologist before sending. For instance, percentages of severe and non-severe patients had to be $100 \%$.

The survey form is given in the Appendix.

To have an overview of the local epidemic spreading, the viral activity was estimated using the emergency department consultation rate for COVID-19 and the local prevalence was estimated using number of RT-PCRs performed and number of positive results for COVID-19 [12].

French departments were used to fit the French health data issued by the health authorities [13].

Data analysis Standard data analysis was performed by a data scientist (M.N.) using three steps methods: (1) automatic data collection using Microsoft form, (2) data cleaning and indexing upon identification data using Python Data Analysis Library 1.0.3 (AQR Capital Management, Lambda Foundry, Inc.), and (3) manual extraction of data of high medical value.

In house web-designed dashboard was designed using Leaflet 1.6.0. No imputation was made for missing data.

\section{Statistical analysis}

Because the patient cohort in our study was not derived from random selection, all statistics are deemed to be descriptive only. Statistical analysis was performed using R software, 
Fig. 1 Flowchart of the study shows the number of participating imaging centers. Note: Data are absolute numbers rounded to the nearest decimal

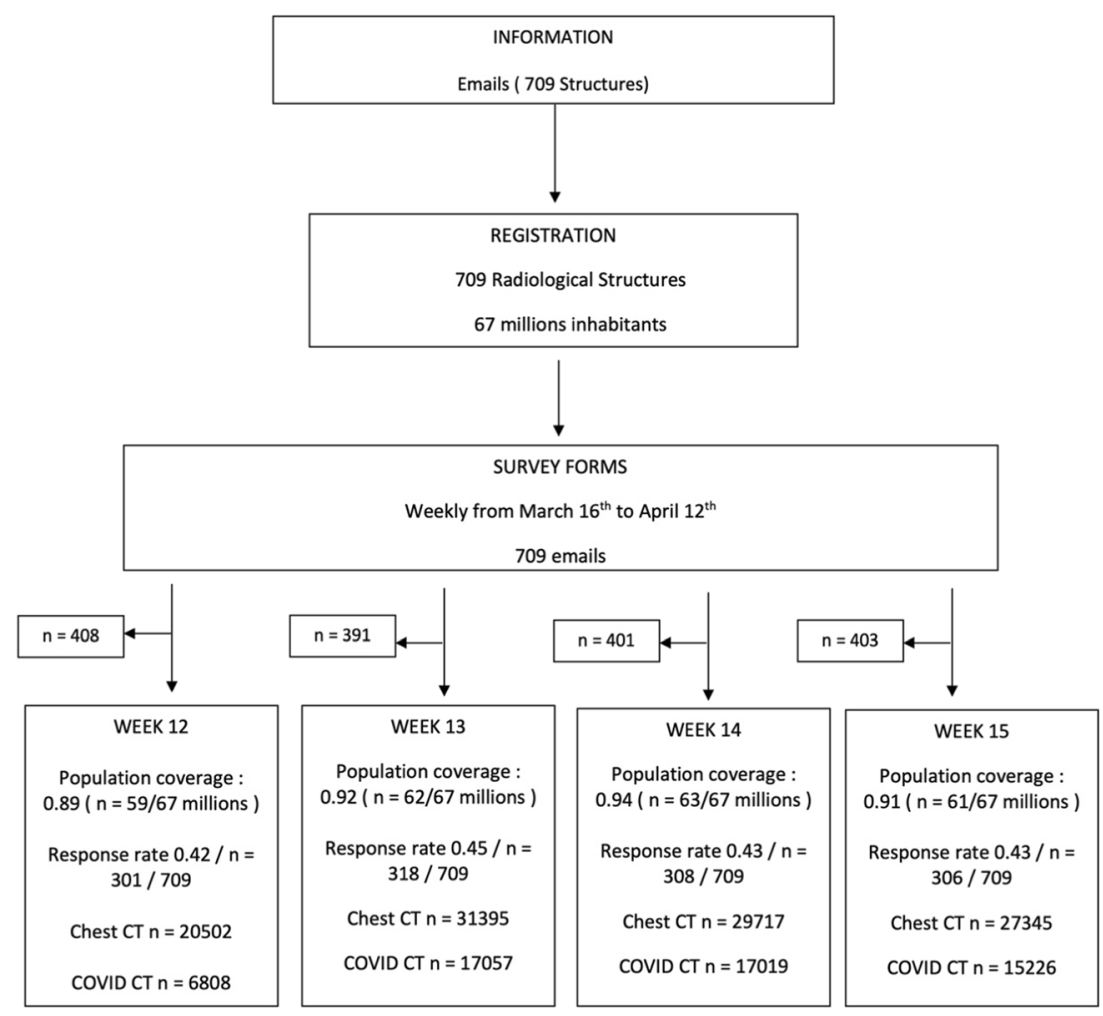

version 3.6.2 (R Foundation for Statistical Computing) and SAS software (version 9.4, SAS institute). Quantitative variables were expressed as means (normal) or medians (skewed), standard deviation (SD), and range. Qualitative variables are described as raw numbers and percentages.

Mean: Test Student.

Skewed: Wilcoxon Mann Whitney.

Dichotomized variables were compared by using the $\chi^{2}$ statistics.

Correlations between CT workflow, French department, and the COVID-19 epidemic markers were tested by a Pearson's correlation tests. The two-sample $t$ test was used to search associations between means and standard deviations in the French departments.

Following medical and biological statistics standards, we set the type 1 error at 0.05 .

Statistical analysis was performed using R software, version 3.6.2 (R Foundation for Statistical Computing) and SAS software (version 9.4, SAS institute).

\section{Results}

\section{Participation and quality}

The survey form was sent to the 709 centers covering all French radiologic centers including university hospitals $(n=$
$32)$, public hospitals $(n=500)$, and private radiologic centers $(n=177)$.

The centers' participation rate over the 4 weeks was stable $0.43 \pm 0.01(0.42-0.45)(304 / 709)$ with respectively 0.42 week $12(n=301 / 709), 0.45$ week $13(n=318 / 709), 0.43$ week $14(n=308 / 709)$, and 0.43 week $15(n=306 / 709)$. The French population coverage represented $90 \%$ of the French inhabitants (60.3 million out of 67 million of inhabitants). Figure 1 gives the flowchart of the study. The internal validity test demonstrated a $0.02 \pm 0.01(0-0.03)$ discrepancy mean rate between responses.

\section{Dedicated imaging device recommendation follow-up}

Among the 174 answers concerning this item, 58.0\% responded that at least one device was dedicated for COVID-19 patients $(n=101 / 174)$. Among these, $91.0 \%$ was for CT scan $(n=92 / 101), 74.2 \%$ for X-ray equipment $(n=75$ / $101), 47.5 \%$ for US devices $(n=48 / 101), 16.8 \%$ for MRI $(n=17 / 101)$, and $11.8 \%$ for interventional room $(n=12 / 101)$.

\section{CT activity}

During the study, 108,959 $\mathrm{CT}_{\text {chest }}$ including 56,110 $\mathrm{CT}_{\text {covid }}$ were performed $(0.52)$. Mean CT scan activity per radiological centers ranged from $75.8 \pm 133(0-1444)$ on week 12 to $99.3 \pm 138.6(0-1147)$ on week 13 . Table 1 gives CT workload along the 4 weeks for the 3 types of radiologic structures. 
The number of $\mathrm{CT}_{\text {chest }}$ and COVID $\mathrm{CT}_{\text {covid }}$ evolved differently during the study period according to the type of centers, whereas in the university hospital, the highest activity was recorded on week 13, it was on week 14 for the public hospital, and on week 15 for the private structure. Figure 2 illustrates the variation of different CT activities and the $\mathrm{CT}_{\text {covid }}$ rate for each type of radiologic centers. Figure 3 gives the evolution of the epidemic over the 4 weeks in the territory.

$\mathrm{CT}_{\text {covid }}$ rate at week 12 was homogeneous whatever the ratio of positive RT-PCR $(0.36 \pm 0.22$ [0-1]). After the week 12, 2 different groups of CT workflow were observed, one where $\mathrm{CT}_{\text {covid }}$ rate remained low and others where mean $\mathrm{CT}_{\text {covid }}$ rate increased over $63 \%$, corresponding to area in which positive RT-PCR rate was higher. The $\mathrm{CT}_{\text {covid }}$ distribution was significantly different at week 13 , week 14 , and week $15(p=0.0003)$. From the week 13, French departments could be classified according to level of epidemic pressure, high or low, 21 and 55 for week 13, 54 and 21 week 14 , and 31 and 43 week 15 respectively. Table 2 gives results for $\mathrm{CT}_{\text {covid }}$ rate among the two different groups of French departments stratified on the RT-PCR rate.

A strong correlation was found between the overall number of RT-PCRs performed in a geographic sub-area and the number of $\mathrm{CT}_{\text {covid }}\left(r=0.73, p=3.10^{-16}\right)$. The emergency department consultation rate over 10,000 for COVID-19 clinical suspicion and the $\mathrm{CT}_{\text {covid }}$ were also highly correlated during the peak of epidemic (from week 13 to $15 ; r=0.64$ [0.61-0.77], $p<0.005$ ) whereas there was no correlation at the beginning of the epidemic (week 12; $r=0.47, p>0.05$ ).

The positive RT-PCR rate was not correlated with the number of $\mathrm{CT}_{\text {covid }}$ within the French departments administrative sub-area $(r=0.24, p=0.25)$.

\section{Discussion}

During the COVID-19 epidemic, the growing trend of increased demands for $\mathrm{CT}_{\text {covid }}$ was associated with a significantly re-oriented CT workflow. Evolution of $\mathrm{CT}_{\text {covid }}$ number from week 12 to week 15 was in accordance with the local epidemic spreading as previously suggested by an online data [14].

The nature of the radiologic structure had an impact on the $\mathrm{CT}_{\text {covid }}$ activities; university hospitals were firstly impacted followed by general hospitals and private structures and all types were finally impacted as previously suggested [15-17]. This different timing could probably be explained by the French health care organization in which university hospitals are commonly the referent health care structure for a large administrative area. Consequently, these hospitals commonly have the largest number of intensive care beds and $\mathrm{CT}$ devices. For private structures, the total of 26,754 


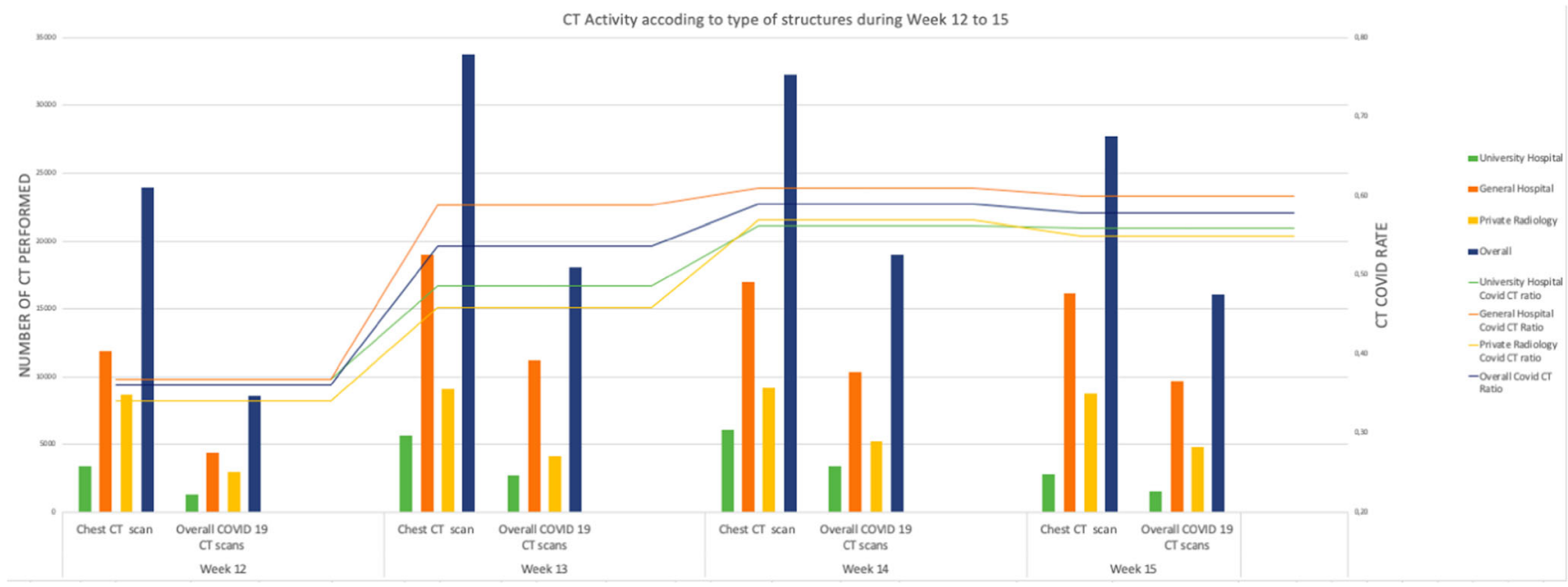

Fig. 2 The variation of the $\mathrm{CT}_{\text {covid }}$ rate during the study within the three types of radiology centers. The histogram illustrates the quantitative numbers of CT performed. The lines illustrate the variation of the mean COVID CT rate among the three types of radiology centers. The number

$\mathrm{CT}_{\text {chest }}$ performed were similar to those observed during a non-epidemic period [18]. Some authors nonetheless reported a 50-80\% decrease in whole CT number in private centers due to COVID-19 [9, 19]. Because we surveyed only the CT activity covering chest, it is difficult to evaluate the global impact of COVID-19 on the whole CT workflow. However, because of a re-orientation of a part of CT activity to COVID-19, we can hypothesize that there was a great impact on other pathologies. Because $52.8 \%$ of the radiologic structures followed the French recommendations to dedicate devices to COVID-19 [20], a funnel-like effect must have been generated, fewer CT devices and more COVID-19 patients leading to less access for other pathologies.

There is also a very interesting point in our results; there was no correlation between either the rate of positive RT-PCR or the local prevalence of COVID-19 and the $\mathrm{CT}_{\text {covid. }}$. In contrast, we observed a strong correlation between the number of RT-PCR tests performed, whatever their results, and the $\mathrm{CT}_{\text {covid }}$. This suggests that $\mathrm{CT}$ was used as screening test to diagnose or rule out COVID-19. There is a large consensus to state that RT-PCR should be the reference for the COVID-19 diagnosis [21-23], despite early data from China suggesting relatively poor diagnostic sensitivity [24]. In a growing pandemic, the risk of false-negative test results increases with the widespread character and the prevalence of the disease. For instance, if we choose a theoretical sensitivity of $90 \%$, for a population of 65 million of inhabitants within which $80 \%$ will be infected, 5.2 million people would be falsely classified as negative, if the whole population had been tested. The sensitivity of CT for COVID-19 is debated but was recently estimated higher than RT-PCR according to Fang et al: In their study, the sensitivity of chest CT was $91 \%$ versus $71 \%$ for RT-PCR $(p<.001)$ [24]. In cases of growing epidemic, the of $\mathrm{CT}_{\text {chest }}$ and COVID $\mathrm{CT}_{\text {covid }}$ seemed to evolve during the study according to the type of centers, whereas in the university hospital, the highest activity was recorded on week 13 , it was on week 14 for the public hospital, and on week 15 for the private structure

sensitivity of the diagnosis test affects the timely management of suspected cases (isolation and medical treatment) and furthers the risk of transmission. In addition to its high sensitivity [25], CT examination also presents two main interests; the test is available immediately and results disposable in less than $15 \mathrm{~min}$ even if it should be kept in mind that imaging features of COVID-19 pneumonia are non-specific [26], sometimes overlapping with other viral pneumonias $[27,28]$. On the contrary, notwithstanding its sensitivity, RT-PCR has the disadvantage of providing delayed results, often in several hours. Furthermore, RT-PCR performance could depend on variations in detection rate from different manufacturers, variations due to patient viral load and/or improper clinical sampling [29]. Therefore, in France, clinical practitioners have integrated CT as an available test to diagnose COVID-19.

This study has limitations. The first one was country coverage, which remains partial. For instance, data on pediatric population in pediatric hospitals are partial, which prevented us from obtaining results on this specific group of patients. Secondly, the declarative mode leads to potential under or over declaration and it was difficult to check data received despite the quality process of the survey. Thirdly, it is likely that involvement of responders was stronger in regions with strong COVID-19 pressure leading to higher response rate. This could introduce bias of overrepresentation. An exhaustive study covering at least $70 \%$ of the centers should have been performed but this objective is likely unreachable. Fourthly, the clinical practices described here concern France only and might not be generalized to other countries in which health care organization, national policy, and disease prevalence could be different. Lastly, availability of a separate CT scanner for COVID-19 patients could have influenced the use of chest $\mathrm{CT}$ imaging as a screening tool; for instance, with 

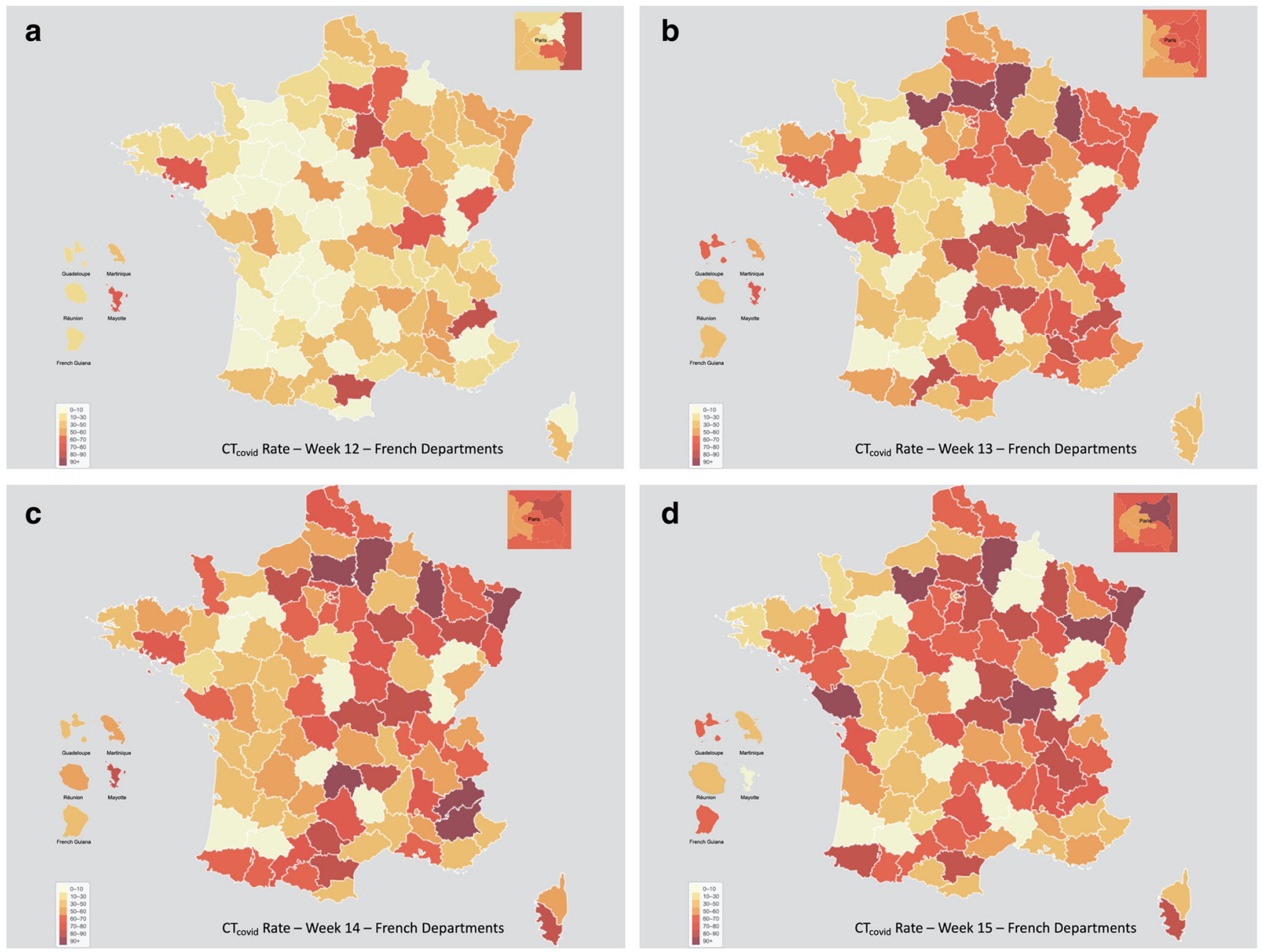

Fig. 3 Graphic analysis of the COVID-19 in France during the study using choropleth maps. a-d COVID CT rate in France using administrative area as unit according to time. A red unit represents a high COVID-19 CT rate level and a yellow unit a low level. COVID CT rate is highest in the north and east of France and diffused during

only one CT scanner, chest $\mathrm{CT}$ may be used less as a screening tool in consideration for other patients. The lack of exhaustive data on this issue did not allow us to analyze this aspect. Further studies are therefore needed.

Table 2 Illustration of the mean and standard COVID CT rate among the two dichotomized groups of geographical areas stratified on the RTPCR rate, the total number of observation $\left(N_{\mathrm{obs}}\right)$, and for each group $\left(N_{\text {obs } 1} / N_{\text {obs } 2}\right)$. The $T$ test assesses significant differences between means among the two groups. Note: Data are absolute numbers and numbers in parentheses are percentages (rounded to the nearest decimal)

$$
N_{\text {obs }}\left(N_{\text {obs } 1} / N_{\text {obs } 2}\right) \quad \text { CP } \quad \operatorname{Mean}_{1} \pm \mathrm{sd}_{1} \quad \operatorname{Mean}_{2} \pm \mathrm{sd}_{2} \quad T \text { test }
$$

Week $1276(38 / 38)$

Week $1376(21 / 55)$

Week $1474(54 / 21)$

$\begin{array}{llll}\text { No } & 0.37 \pm 0.23 & 0.35 \pm 0.18 & - \\ \text { Yes } & 0.53 \pm 0.22 & 0.64 \pm 0.18 & 0.03 \\ \text { Yes } & 0.59 \pm 0.19 & 0.67 \pm 0.13 & 0.03 \\ \text { Yes } & 0.52 \pm 0.19 & 0.69 \pm 0.17 & 0.0003\end{array}$

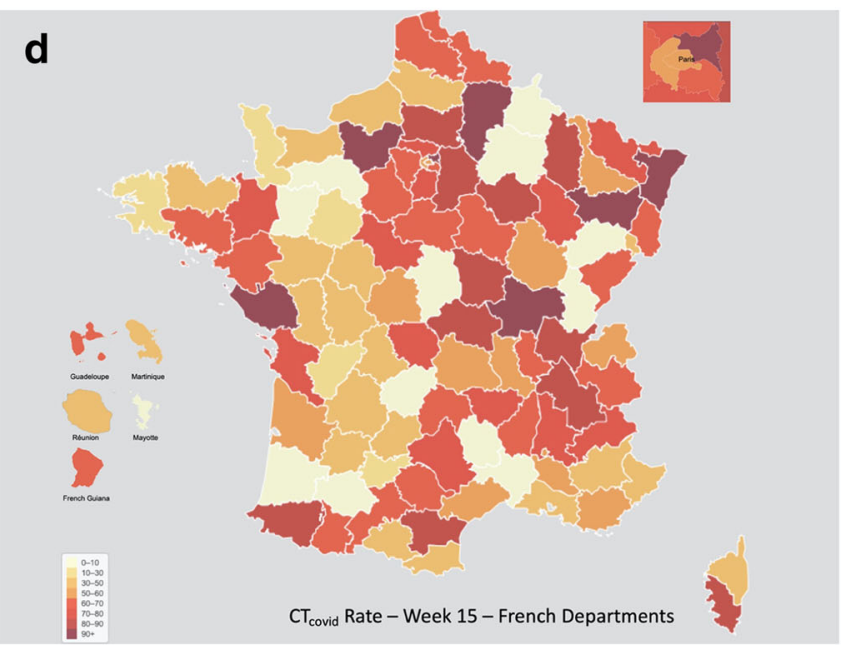

the 4 weeks of the study. Considering that the epidemic peak was on the week 13, COVID CT rate remains high during the 4 weeks of the study. a $\mathrm{CT}_{\text {covid }}$ rate for week 12. b $\mathrm{CT}_{\text {covid }}$ rate for week 13. $\mathbf{c} \mathrm{CT}_{\text {covid }}$ rate for week 14. d $\mathrm{CT}_{\text {covid }}$ rate for week 15

\section{Conclusion}

Impact of COVID-19 on CT workflow was strong due to the number of examinations performed to a certain extent due to its diagnosis sensitivity. This study demonstrates the role of all types of radiology centers in the health care policy in France during this epidemic.

Acknowledgments The authors would like to acknowledge the Covid Imaging Network SFR for data collection.

Funding information The authors state that this work has not received any funding.

\section{Compliance with ethical standards}

Guarantor The scientific guarantor of this publication is Pr Jean Paul Beregi on behalf of the scientific committee consisting in Pr Bartoli, Pr Léderlin, and Pr Saulnier. 
Conflict of interest The authors of this manuscript declare no relationships with any companies whose products or services may be related to the subject matter of the article.

Statistics and biometry Dr. Farida Enikeeva, $\mathrm{PhD}$, in Statistics from the University of Poitiers is one the author of the article. Dr. Enikeeva therefore provided advices for data curation and statistical analysis.

Informed consent Written informed consent was waived by the Institutional Review Board.

Ethical approval Institutional Review Board approval was obtained.

\section{Methodology}

- prospective

- observational

- multicenter study

\section{References}

1. COVID-19 Map - Johns Hopkins Coronavirus Resource Center. https://coronavirus.jhu.edu/map.html. Accessed 18 Apr 2020

2. COVID-19 : EN DIRECT. In: SFR e-Bulletin. https://ebulletin. radiologie.fr/covid19. Accessed 24 Apr 2020

3. Tableau de bord COVID-19. In: Tableau de bord COVID-19. https://dashboard.covid19.data.gouv.fr. Accessed 18 Apr 2020

4. Coronavirus COVID-19. In: Haute Autorité de Santé. https://www. has-sante.fr/jcms/p_3165982/fr/coronavirus-covid-19. Accessed 4 May 2020

5. COVID-19 : EN DIRECT. In: SFR e-Bulletin. https://ebulletin. radiologie.fr/covid19. Accessed 4 May 2020

6. ACR Recommendations for the use of Chest Radiography and Computed Tomography (CT) for Suspected COVID-19 Infection. https://www.acr.org/Advocacy-and-Economics/ACR-PositionStatements/Recommendations-for-Chest-Radiography-and-CTfor-Suspected-COVID19-Infection. Accessed 24 Apr 2020

7. RCR position on the role of CT in patients suspected with COVID19 infection | The Royal College of Radiologists. https://www.rcr. ac.uk/college/coronavirus-covid-19-what-rcr-doing/clinicalinformation/rcr-position-role-ct-patients. Accessed 24 Apr 2020

8. Dennie C, Hague C, Lim RS et al (2020) The Canadian Society of Thoracic Radiology (CSTR) and Canadian Association of Radiologists (CAR) Consensus Statement Regarding Chest Imaging in Suspected and Confirmed COVID-19. 23

9. Cavallo JJ, Forman HP (2020) The economic impact of the COVID-19 pandemic on radiology practices. Radiology 201495. https://doi.org/10.1148/radiol.2020201495

10. http://reseaucovidimagerie.fr/. Accessed 28 Apr 2020

11. Epidemiology for the uninitiated | The BMJ. https://www.bmj.com/ about-bmj/resources-readers/publications/epidemiologyuninitiated. Accessed 11 Apr 2020

12. Info Coronavirus COVID-19 - Stratégie de déconfinement. In: Gouvernement.fr. https://www.gouvernement.fr/info-coronavirus/ strategie-de-deconfinement. Accessed 8 May 2020

13. Géodes - Santé publique France - Indicateurs : cartes, données et graphiques. $\mathrm{https}: / /$ geodes.santepubliquefrance. $\mathrm{fr} / \mathrm{Ac}=$ indicator\&f= $0 \& \mathrm{i}=$ covid_hospit.hosp\&s $=2020-03-24 \& \mathrm{t}=\mathrm{a} 01 \&$ view $=$ map 2 . Accessed 4 May 2020
14. (2020) CT imaging - the impact of COVID-19 on radiology. In: Aidoc. https://www.aidoc.com/blog/ct-imaging-volumes-covid19/. Accessed 24 Apr 2020

15. Politi LS, Balzarini L (2020) The radiology department during the COVID-19 pandemic: a challenging, radical change. Eur Radiol. https://doi.org/10.1007/s00330-020-06871-0

16. Devaraj A (2020) Important lessons for infection control in radiology departments during the COVID-19 pandemic. Eur Radiol. https://doi.org/10.1007/s00330-020-06873-y

17. Mossa-Basha M, Meltzer CC, Kim DC, Tuite MJ, Kolli KP, Tan BS (2020) Radiology department preparedness for COVID-19: radiology scientific expert panel. Radiology 200988. https://doi.org/ 10.1148/radiol.2020200988

18. ameli.fr - $\mathrm{N}^{\circ} 50$ - L'activité des médecins libéraux à travers la CCAM. https://www.ameli.fr/lassurance-maladie/statistiques-etpublications/rapports-et-periodiques/points-de-repere/n-50actesccam-en-secteur-liberal-en-2016.php. Accessed 1 Jul 2020

19. Kikoom (2020) CRISE COVID-19 - Au front de la pandémie pour maintenir la continuité des soins pour tous(tes) les patient(e)s, l'imagerie médicale libérale est en grave péril » FNMR - Spécial Covid-19. In: FNMR - Spécial Covid-19. https://fnmr.app/crisecovid-19-au-front-de-la-pandemie-pour-maintenir-la-continuitedes-soins-pour-toustes-les-patientes-limagerie-medicale-liberaleest-en-grave-peril/. Accessed 8 May 2020

20. Ding J, Fu H, Liu Y, and al (2020) Prevention and control measures in radiology department for COVID-19. Eur Radiol https://doi.org/ 10.1007/s00330-020-06850-5

21. West CP, Montori VM, Sampathkumar P (2020) COVID-19 testing: the threat of false-negative results. Mayo Clin Proc: S0025619620303657. https://doi.org/10.1016/j.mayocp.2020.04. 004

22. Raptis CA, Hammer MM, Short RG, and al (2020) Chest CT and coronavirus disease (COVID-19): a critical review of the literature to date. AJR Am J Roentgenol 1-4. https://doi.org/10.2214/AJR. 20.23202

23. Liu J, Yu H, Zhang S (2020) The indispensable role of chest CT in the detection of coronavirus disease 2019 (COVID-19). Eur J Nucl Med Mol Imaging:1-2. https://doi.org/10.1007/s00259-02004795-X

24. Fang Y, Zhang H, Xie J et al (2020) Sensitivity of chest CT for COVID-19: comparison to RT-PCR. Radiology 200432. https:// doi.org/10.1148/radiol.2020200432

25. Xu B, Xing Y, Peng J et al (2020) Chest CT for detecting COVID19: a systematic review and meta-analysis of diagnostic accuracy. Eur Radiol. https://doi.org/10.1007/s00330-020-06934-2

26. Fu F, Lou J, Xi D et al (2020) Chest computed tomography findings of coronavirus disease 2019 (COVID-19) pneumonia. Eur Radiol. https://doi.org/10.1007/s00330-020-06920-8

27. Liu J, Chen T, Yang H et al (2020) Clinical and radiological changes of hospitalised patients with COVID-19 pneumonia from disease onset to acute exacerbation: a multicentre paired cohort study. Eur Radiol. https://doi.org/10.1007/s00330-020-06916-4

28. Bai HX, Hsieh B, Xiong Z, and al (2020) Performance of radiologists in differentiating COVID-19 from viral pneumonia on chest CT. Radiology 200823. https://doi.org/10.1148/radiol.2020200823

29. Xie C, Jiang L, Huang G et al (2020) Comparison of different samples for 2019 novel coronavirus detection by nucleic acid amplification tests. Int J Infect Dis 93:264-267. https://doi.org/10. 1016/j.ijid.2020.02.050

Publisher's note Springer Nature remains neutral with regard to jurisdictional claims in published maps and institutional affiliations. 


\section{Affiliations}

Guillaume Herpe $^{1,2}$ (D) Mathieu Naudin ${ }^{2} \cdot$ Mathieu Léderlin $^{3} \cdot$ Farida Enikeeva $^{2} \cdot$ Olivier Boumendil $^{4}$. Lucie Cassagnes $^{5} \cdot$ Madeleine Cavet $^{6} \cdot$ Kathia Chaumoitre $^{7} \cdot$ Philippe Feuerstein $^{8} \cdot$ Isabelle Fitton $^{9} \cdot$ Violaine Flory $^{10}$. $^{2}$ Cornelia Anna Freitag ${ }^{11}$. Jean Yves Gaubert ${ }^{12}$. Jules Gregory ${ }^{13} \cdot$ Hubert Nivet $^{14}$. Mickaël Ohana ${ }^{15} \cdot$ Isabelle Petit $^{16}$. Nicolas Sans ${ }^{17}$. Mathilde Wagner ${ }^{18} \cdot$ Rémy Guillevin $^{19} \cdot$ Pierre-Jean Saulnier $^{20}$ • Jean-Michel Bartoli ${ }^{21}$. Jean Pierre Tasu ${ }^{22}$. Jean-Paul Beregi ${ }^{23}$

1 University Hospital Centre Poitiers, Radiology, 2 rue de la milétrie, 86000 Poitiers, Vienne, France

2 Université de Poitiers Laboratoire de Mathématiques et Applications, Dactim Mis Team, 86073 Chasseneuil, NouvelleAquitaine, France

3 University Hospital of Rennes, Radiology, Rennes, Ille-et-Vilaine, France

4 TELEDIAG, 69009 Lyon, France

5 CHU Clermont-Ferrand, Service de Radiologie B, 63003 ClermontFerrand, France

6 CTM groupe, 34967 Montpellier, Occitanie, France

7 APHM, Radiology, 13015 Marseille, PACA, France

8 Groupe Hospitalier de la Region de Mulhouse et Sud Alsace, Radiology, 68051 Mulhouse, Grand Est, France

9 European Hospital Group Georges-Pompidou, Radiology, 75908 Paris, Ile-de-France, France

10 Centre Hospitalier Universitaire de Nice Hôpital Pasteur, Radiology, 06189 Nice, Alpes Maritimes, France

11 CHU Nimes, 30029 Nimes, Gard, France
12 CHU Timone, Radiology, 13385 Marseille, BDR, France

13 APHP Hopital Beaujon, Paris, France

14 Imadis téléradiologie, 69002 Lyon, Rhône, France

15 Nouvel Hôpital Civil, Radiology, 67000 Strasbourg, Alsace, France

16 CHRU de Nancy, RADIOLOGY, 54500 Nancy, Grand Est, France

17 CHU Purpan, Service central d'imagerie médicale, 31059 Toulouse, Haute-Garonne, France

18 Sorbonne Université, Radiology, 75013 Paris, Île-de-France, France

19 University Hospital Poitiers, Radiology, Poitiers, France

20 CHU Poitiers, Clinical Investigation Center CIC1402, 86021 Poitiers, Vienne, France

21 La Timone Hospital, Radiology, Marseille, BDR, France

22 CHU de Poitiers, Service de Radiologie, Poitiers, France

23 University Hospital Center of Nîmes, Radiology, Nîmes, Gard, France 